\title{
Emerging information technologies in accounting and related security risks - what is the impact on the Romanian accounting profession
}

\author{
Sînziana-Maria Rîndașu a,1 \\ ${ }^{a}$ The Bucharest University of Economic Studies, Romania
}

\begin{abstract}
This study investigates whether aspiring and professional accountants understand the benefits and security challenges brought by emerging technologies such as: Big Data, data analytics, cloud computing and mobile technologies. 115 participants took part in a survey during January and February 2017, all having at least one year of practical experience in accounting or audit and $80 \%$ of them being affiliated with national or international accounting professional bodies. The research has three key findings: (1) Professional accountants and auditors are having in average a theoretical knowledge of the emerging technologies in the accounting field, but they still need to enhance their skills to exploit them efficiently, (2) Mobile technologies started to be adopted by the Romanian practitioners and (3) The profession has become aware of the security risks brought by emerging technologies in the digital accounting. The accounting profession is on the verge of change and the practitioners do not yet possess sufficient skills regarding the analyzed emerging technologies. As per this, the professional bodies and academic environment should reassess their curricula to enforce the necessary changes for preparing practitioners to successfully face the future challenges and avoid their replacement by other professions more qualified.
\end{abstract}

Keywords: cloud computing, mobile technologies, Big Data, data analytics, security threats

1 Corresponding author: Sînziana-Maria Rindașu, Bucharest University of Economic Studies, Romania; tel. (+4)0748070616; email address: sinziana_rindasu@yahoo.com 


\section{JEL codes: L86, M41, O33}

\section{Introduction}

Nowadays the business environment has become extremely dynamic due to the rapid changes in the information technology field, driven by competition and performance. New technologies are designed to cover the broad range of economic demands, such as Big Data, data analytics, mobile technologies and cloud computing platforms, all of these meant to offer flexibility, economies of scale, mobility and more accuracy.

The accounting field is subject to this new era of change. The IoE (Internet of Everything) era is reshaping the accounting profession following the current needs of the organizations. Artificial intelligence and process automation are taking over the redundant and repetitive tasks performed by the professionals, creating room for more complex activities, such as analysis and business advisory.

Researchers are emphasizing that some processes from the accounting field might be taken over by robotics (Frey and Osborne, 2013) and part of the accounting profession will disappear. Even so, along the time we have observed that technology is not meant to replace the professionals, but to create the necessary means for practitioners to focus on activities that create more value for the organization (Richins et al., 2016).

The accountants need to develop new skills to work efficiently with emerging technologies such as cloud platforms, Big Data, data analytics and mobile technologies. As the academic environment represents the connection between the aspiring accountants and the profession, researchers emphasize that the universities should provide their students with a proper support to gain at least theoretical knowledge in the IT area (Stanciu \& Bran, 2015).

According with the study conducted by ACCA and IMA (2015), new roles are emerging in the accounting profession that will focus not only on accounting and finance, but also on information technologies. Moreover, accountants and auditors are expected to demonstrate sufficient skills for protecting sensitive information, by implementing and assessing controls involving systems and applications (Chorafas, 2008; PCAOB, 2010).

Besides the support given by professional bodies such as ACCA, ICAEW and IMA, Big 4 companies have realized the potential brought by the technological evolution as well as the associated risks. As per this, they started providing guidelines and even creating tools, like Secure Terrain and Terrain Intelligence, based on centralized platforms along with Big Data and data analytics, which help companies to assess and monitor their cyber-security risks (PWC, 2016). 
The current economic context is driven by speed and increased volumes of data and in this regard, the real-time management and reporting are vital for companies in the decision-making process. Even so, Vasarhelyi et al. (2008) state that the profession is still progressing traditionally, instead of keeping pace with the businesses.

In order to understand the advantages and challenges for the accounting profession in regard to these emerging technologies and trends, the paper discusses the main characteristics of cloud computing, big data and analytics along with mobile technologies, with the purpose of better understanding the potential impact that these technologies might have in the accounting field, especially in regard to data security. The second part of the paper is focusing on the perception of Romanian aspiring and professional accountants and financial auditors concerning the benefits brought by the technological progress and on the associated challenges, assessing if they are completely aware of the potential changes in the accounting profession. The present paper aims to stimulate the debate and research on the topic, being identified a moderate focus in the Romanian literature.

\section{Literature review - Information technologies and new challenges for the accounting profession}

The digital evolution in the accounting field is not a new subject as the real digitalization process has started in the 90s along with the development of accounting information systems and it is then followed by the ERP systems, cloud computing platforms and Big Data. Now, from a technological point of view, the new aspect in the accounting field is represented by the usage of mobile technologies, followed by the need of analyzing big volumes of data, using data mining and analyzing techniques.

However, international professional bodies such as ACCA(2013a) and ICAEW (2015) consider cloud computing platforms as a technology that might yet influence and change the profession, along with Big Data, process automation, mobile and online technologies. Despite the fact that cloud computing platforms, Big Data and data analytics are not theoretically new concepts from a technological perspective, from the practical point of view these are still considered to be emergent, and currently their usage is mandatory as the volume of data is still increasing.

Until recently, cloud computing platforms and data analysis using data mining techniques have been used only by certain types of companies in particular industries. However, now we can notice the need of using these technologies in the accounting field and, in this current digital context, migration is not anymore an option, but rather a necessity. 
Cloud computing platforms have started to develop in the late 90's and the main idea of this new concept was "unlimited technological access to data", a concept mentioned for the first time in 1997 as the study made by Giordanelli and Mastroianni (2010) states. Cloud computing platforms are mainly about storing the data outside the company, in a data storage center, without the need of installing additional pieces of equipment. Although the concept seems simple, this technology is still in the developing stage, due to the complexity of the applications and wide variety of platforms.

The decision of migrating to cloud platforms seems to be driven by the general trend and market needs. If once, the question was to migrate or not, now this has been changed with when?. The study conducted by Jones et al. (2017), has highlighted that in the UK public sector, cloud adoption has already started, to be prepared to face the technological challenges.

Cloud computing platforms bring a broad range of benefits, which have the potential of creating competitive advantages for companies. Some of the significant gains in the accounting field are the economies of scale (Singh et al., 2004; Armbrust et al., 2009), an increased level of flexibility and mobility (Carroll et al., 2011). This technology represents the base for real-time reporting and analysis that has become undoubtedly crucial for this new era of speed. However, it is important to keep in mind that not only large companies might need to consider migrating to a cloud platform, but also SMEs, which have the same motivation of adopting this emerging technology (Caldarelli et al., 2017).

Besides the variety of benefits given by the usage of cloud platforms, there is also a set of risks, including security, availability and data integrity, along with the long term platforms viability (Shayan et al., 2014; Brandas et al., 2015; Johns, 2016; Joshi et al., 2017). Even so, for some companies, the migration towards cloud platforms represents an increase in the data security (IBM, 2009), suggesting that information security depends on the architecture of the systems, even if we are talking about inhouse systems or cloud platforms.

A critical issue regarding cloud computing security relates heavily to the human factors. Companies usually have as mindset better performance and cost efficiency when choosing a new technological trend, such as cloud computing or mobile technologies. Still, studies have shown that employees or future professionals are not completely aware of the proper behavior when using these technologies (Scheponik et al., 2016; Walterbusch et al., 2017), fact that leads to an increased risk of accidental data exposure.

Another technology that will influence the accounting profession is Big Data, along with data analysis, which in most cases are used together with cloud platforms. As it has been presented before, the current speed of data creation is increasing with every second and in this regard, the analysis of information using the current techniques is 
not easily made and it doesn't adequately reflect the reality. Unlike modern ERP systems that contain mostly structured data with clear connections, Big Data offers the advantage of analyzing unstructured or semi-structured data from the entire economic environment, which has the potential of changing our perception of certain economic trends. Regarding the perception of accountants in practically use Big Data as a tool to create more accurate forecasts and to appropriately address particular problems, research has shown that the overall feedback is positive (Al-Htaybat \& Alberti-Alhtaybat, 2017).

To optimally analyze significant volumes of information, the Big Data technology shows an increased potential for the accounting profession. The main benefits are: quicker fraud identification, increased productivity, costs reduction, enhancing the degree of understanding the economic trends and increased accuracy (Russom, 2011). Nonetheless, it has the potential of becoming a key differentiator for companies (Mayer-Schönberger, 2013), enhancing financial forecasts and sensitive analyses Cokins (2013).

It is important to keep in mind that Big Data means data, which is most of the cases it is intangible. This is the main reason why when having cost reduction as a benchmark when using this technology, we must not only relate to the value of the data itself, as will prove in most cases impossible to quantify (Huang et al., 2016) but rather on the advantages brought by this new knowledge.

Other benefits associated with Big Data usage in the accounting and financial fields are related to the facilitation of the real-time reporting process (McKnight, 2015), providing in this way a more detailed support for the decision-making process and identifying the risks in real time. It also supports the vital role of the information for companies, which has become an important part of the value creation process, being even considered an asset (ACCA, 2013b). As in the case of cloud platforms, Big Data and data mining techniques induce a set of challenges. These are focusing on the lack of competencies of the practitioners in the field of Big Data (ACCA, 2013a), the lack of proper technologies and optimal analysis techniques, data security and legal conformity (E\&Y, 2014).

Another new and significant challenge to the accounting profession is represented by the mobile technologies, which succeed to enhance the quality of the services due to a higher degree of connectivity, crossing the geographical borders (ACCA, 2013b). Moreover, the usage of mobile technologies will improve the real-time reporting process (Trigo et al., 2014) and the companies will have the opportunity to enhance their agility in response to the customers' demands. Their usage in the professional activity allows availability and analysis of the data in real-time, aspect that is essential for the persons responsible for the decision making process. Also, there is the possibility of creating applications for a more efficient analysis, data being instantly available (push notifications). In this regard, the researchers consider 
that this emerging technology increases the level of flexibility and productivity (Stieglitz \& Brockmann, 2012) and improves the quality of collaboration between coworkers (Johns \& Gratton, 2013).

Nonetheless, mobile technologies can be used to input data or make payments, facilitating in this way the processes and the access to data. In many cases, these mobile technologies are associated with cloud platforms with the purpose of extending the availability of the information. An important step in efficiently incorporating these emerging technologies in the accounting profession is their introduction in academic curricula. However, research as shown that the professors and the academia tend to disregard the expanding power of information technology in this field (Zarei et al., 2014; Watty et al., 2016). The professors' lack of technical skills might represent in this case an impediment for students to adapt and adopt efficiently new technologies.

\subsection{The overview of emerging technologies in the local accounting context}

Even though benefits of the emerging technologies presented above are considered universally accepted, it is important to understand the local impact of these technologies, in regard to the accounting profession.

In Romania, the issues of emerging technologies in the accounting field have been addressed during the last years by researchers, focusing on the need that practitioners should extend their skills to use these technologies efficiently.

Cloud computing platforms are considered by Romanian accounting researchers an important topic, as it can bring a variety of benefits that will result in a general enhancement of the accounting processes, by excluding manual repetitive processing and digitalize these actions. In the study performed, Ionescu et al. (2014), shows that the cloud automation not only reduces the time of handing physical documents by digitalizing this process, but also the cloud solutions can have as a result a decrease of errors, by quicker identifying duplicate documents and transactions. Moreover, this study emphasizes another crucial aspect in regards to cloud implementation: the accountants are more focused on the business rather than on the technology, fact that might impact cloud adoption in accounting departments. The results of the study conducted by Ionescu et al. (2014) is in line with the expected benefits of could adoption, as emphasized in international research. The main drawback of cloud implementation, as stated by the authors, refers to security aspects in the cloud. Even though this issue might not be entirely accurate, as prior research has proven that not always cloud adoption decreases the security level, but rather the contrary. Still, from this outcome we can observe that the accounting professionals understand the necessity of data security. 
Another study concerning the willingness of accountants in regards to accepting cloud solutions (T,ugui \& Gheorghe, 2014) has emphasized that the profession shows a high level of interest in the benefits brought by cloud computing and consider that migration as representing a positive aspect. However, we must not overlook that the usage of new technologies requires the existence of prepared professionals that will be able to exploit these resources efficiently.

Mangiuc (2017) highlights the fact that the accounting profession has a significant role in the adoption and acceptance of emerging technologies, such as cloud accounting. The author considers that the accountants should act as an intermediary between the IT departments and the management, by advising the suitable IT solutions that can add value to the organization, after performing appropriate analyses based on cost efficiency. The most significant benefits identified in this study are considered to be: a higher degree of innovation, rapidity and increased accuracy. By analyzing the challenges presented, two important drawbacks are addressed: the fact that most cloud providers do not offer a solution for local backup and the rigidity of cloud solution compared with desktop solutions.

The economy of scale, as a benefit of cloud adoption is an extremely disputed topic. Romanian researchers (Ionescu \& Bendovschi, 2014; Mangiuc, 2017) draw attention to the fact that on the long term the cloud solutions might be in fact more expensive than in house solutions. Ionescu and Bendovschi (2014) analyze the cost efficiency of cloud platforms for SMEs and the research points out that unless carefully examined, there is the possibility that the cloud solution will not provide all the time the cost-efficiency expected. Nonetheless, a study performed taking into consideration medium companies and an average cost for particular cloud solutions, as per the rates available in Romania, has shown a decrease of overall costs (Ionescu et al., 2013).

Due to the dependency of IT enhancements that can facilitate the operational processes of organizations, the security aspects seem to be the biggest drawback identified by the researchers in the Romanian accounting profession. While some accounting practitioners rely heavily on the security of data in transit and certifications of the cloud supplier, for the IT professionals the overall security of the applications and the existence of a disaster recovery plan is considered to be a key differentiator (Ionescu \& Tudoran, 2013). Moreover, shared data and multitenancy issues are deemed to be a major drawback for the accounting professionals (Stanciu, 2012). This outcome shows that there are different expectations between the financial and IT departments when it comes to the selection of the cloud supplier, an aspect that can influence the overall security of the solution, in the scenario in which the accounting department should mitigate any possible migration.

Big data has also been an issue of considerable interest during the last years in Romanian accounting research. Stanciu (2015) highlights as a result of the empirical 
research conducted that the aspiring accountants might not yet have enough knowledge on retrieving and manipulating big volumes of data efficiently. This conclusion is also supported by the investigation performed by Stanciu and Rîndașu (2017) after analyzing the study programs of accounting faculties from Romania, concluding that the existing curricula do not focus enough on emerging technologies, such as cloud computing, Big Data and data mining, through bachelor and master programs, in order to create a sufficient base for future practitioners to respond efficiently to the current needs of the economy. This result is consistent with international research and reveals that the academic environment might be restrictive when it comes to emerging technologies, preventing students for gaining in some cases sufficient knowledge to adequately respond to the current job demands.

Mobile technologies are being adopted more quickly and efficient compared with the other emerging technologies presented (Stanciu, 2012; Tudoran \& Ionescu, 2014), point that can be explained through the general preference of using smartphones and tablets. Benefits such as continuous access, better connectivity and reduced costs, when are used with cloud platforms (Brandas et al., 2015), qualifies mobile technologies as a key differentiator in the current local economical context. However, some of the most addressed drawbacks and challenges of this technology are limited resources, small screens and connectivity issues. The general trend of adopting the BYOD (Bring Your Own Device) concept, comes with a broad range of security issues that must be addressed, such as: physical security of the device, software vulnerabilities and access control.

\section{The impact of existing and emerging information technologies on data security in digital accounting}

The technological progress brings obvious benefits for the companies and the development of the profession, helping to reduce the costs by increasing the productivity level and enhancing process automation. However, we must be aware that each of these new technologies has a common challenge, the security of sensitive data. In this section of the paper, we will analyze data security from the perspective of these existing and emerging technologies that influence the accounting field, along with the exposure of the possible impact of security incidents.

The international accounting bodies emphasize the necessity to develop the appropriate skills for protecting the data and assuring confidentiality, integrity and availability of the information by using efficient controls. By adopting these technologies in the accounting field, the risk of sensitive data exposure increases and in this regard the practitioners need to understand the necessity of preventing security incidents, even more now as the largest amount of vulnerable data is produced by the accounting and financial departments. 
The causes of security incidents are diverse, the primary source being the external attacks, followed then by the incorrect configuration of the systems, the lack of appropriate skills of the employees, excessive access rights, accidental exposure of sensitive data, weak or implicit passwords and the lack of effective preventive controls.

Aiming to analyze the way in which the information security is affected by the existing and emerging information technologies used in the accounting and audit field, firstly we should identify the main causes that affect the characteristics of data.

\subsection{Cloud computing platforms and security threats}

A cloud platform model can be defined based on the expectancies of the users, and in practice, these can be classified by two criteria: according to the delivery model of the service and by the implementation method (Buyya et al., 2010). According to the delivery model, the base of any platform is represented by IaaS - Infrastructure as a Service, where the users have control over the entire cloud platform and in practice, the IaaS is used by system administrators and represents the base of the entire platforms. Due to this, any existing vulnerability in Iaas will influence the other models. The second type, PaaS (Platform as a Service) gives the users the right to manage the applications, but not the platform, being often used by the developers. The last model is represented by SaaS - Software as a Service being the most used type of model - everything that is available online is included in this category (Yahoo Mail, Gmail etc.). The SaaS users have restricted privileges that allow them only to use the applications without having the right to modify them - the accounting applications are available in this last model.

Another classification of cloud platforms is based on the method of implementations, which incorporates four models (Mell \& Grance, 2009):

1. public - is available for all internet users;

2. private - is used by particular categories of users, presenting an increased level of data security compared with the public model;

3. community - is quite similar to the private model regarding information security and governance, offering at the same time the flexibility of the public model;

4. hybrid - represents a combination of two models (private, public or community), being considered the most complex model.

In the case of cloud computing technologies, the security of data differs according to the way of usage. When the platforms are used strictly to store data, the risk associated with data exposure is equal to the risk generated by transmitting the information online, when the data is encrypted. However, taking into consideration the need to process and manage data, the usage of cloud platforms just for storing purposes does not bring significant benefits besides $24 / 7$ access. On the other hand, in the case in which the platforms are used to manipulate data, the information has 
to be decrypted and this way an additional level of protection is needed to ensure data confidentiality and integrity.

Selecting a cloud provider is a decision that needs to be based on a detailed analysis of the safety offered, such as the type of data encryption, mainly on the type of algorithm used, logical separation, the existence of a disaster recovery plan, the systems level of performance and the availability of information.

Analyzing the taxonomy of cloud platforms presented above, we can notice that the financial and accounting applications are in the SaaS model, where the users cannot configure the application. Due to this, the users are not allowed to control the security measures implemented by the cloud provider, unless they will want to use all three models. In this case, the economies of scale benefits are not achievable anymore, this solution being equivalent to an in-house extended network that allows the access to internal and external users of the company.

When migrating to a cloud platform is mandatory to know and understand the basic principles of the developing model of the platform and accordingly to the implementation method, the optimal solution for the accounting field is represented by the private model due to security reasons.

The security incidents in the cloud are often caused by the lack of a good set of principles. The attack from 2014 against Apple proves how the shortage of a solid security framework regarding the safety of user's passwords and blocking access after a number of failed authentications can be anytime turned into a cyber-security attack. Although the company has been alerted previously that the users' data is not secured being susceptible to a brute force attack, the patching of the vulnerability has not been timely applied and as a result, private users' photos have been exposed, is a classic example of broken credentials. This incident demonstrated that security incidents could affect any company despite the size when proper detection and correction controls are not in place.

Migrating towards cloud computing platforms must comply not only with a good set of security practices and systems functionality, but also with the legal requirements. In 2016, at the European Union level there has been a change in the regulations regarding data protection as an effect of the technological progress and the member states must enforce these new laws until 2018. At this moment the law that is being applied is the EU Directive 95/46/EC Directive from 1995, which is not so restrictive with cloud providers as the new regulation.

\subsection{Big data and security threats}

The five characteristics that stand at the base of the Big Data concept are: volume, velocity, variety (Laney, 2001), variability and complexity (SAS, 2013) and each one of these characteristics generates risks regarding data security. 
1. Volume - two main issues can be identified: often the cyber-attacks target big amounts of data, due to the diversity and possible benefits, while the second threat is generated by the storage in the cloud of a significant volume of data, a scenario that can create uncertainty regarding the security and confidentiality.

2. Velocity - the issue of time-sensitive data emerges, due to the higher level of associated risks.

3. Variety - is referring to the taxonomy of data stored, including here structured, semi-structured and unstructured data that can be linked to confidentiality issues due to the wide range of differences.

4. Variability - can influence the security especially when peaks of activity are recorded, the best solution being the migration to cloud to handle the increased volume of data, fact that can generate the issues regarding the security of the data in the cloud.

5. Complexity - it enhances the problem of security because the data is collected from multiple sources that might require different types of protection.

The leading solutions to prevent security incidents are access management, implementing preventive controls, monitoring data access and choosing an optimal infrastructure. Moreover, in the case of using Big Data, data analytics and cloud technologies a solution to avoid data leakage or exposure is to use the appropriate encryption type. Currently, the best one is the 256-bits encryption as the previous encryption standard of 128-bits started to be faulty due to the exponential increase in capacity of the computers. Also, to prevent the creation of new vulnerabilities, the practitioners in the accounting and financial field should make sure that they are using and transmitting sensitive data through secured channels, without affecting the confidentiality of the information.

\subsection{Mobile technologies and security threats}

The mobile technologies also generate a higher risk of data exposure, due to improper access management, ineffective controls and the lack of security. Concepts like BYOD (Bring Your Own Device) allowed employees to use their personal mobile technologies in performing their activity and this has proven to be a way of increasing the productivity of employees and providing more flexibility at the same time (Deloitte, 2013; Bradley et al., 2012).

However, this new concept increases the risk of data exposure and theft (Morrow, 2012), the real challenge being the physical security and access control to sensitive corporate data (Thielens, 2013), along with the lack of sufficient controls and policies that will prevent security incidents (Kearns, 2016). 
By analyzing the connectivity methods, the issue of Wi-Fi network security emerges, more precisely of the types of technologies used to transmit and encrypt data that due to the technological progress has become sensitive to cyber-attacks (Gold, 2011). Another important aspect of mobile technologies security is represented by the operating systems, which are frequently updated and even so there are recommendations to upgrade the devices to the newest software version (FBI, 2012). However, there is the possibility of increasing the exposure risk due to zero-day vulnerabilities.

As an overall idea regarding mobile technologies, the practitioners that use mobile devices for business purposes must guard the security of the information by using passwords with an increased level of complexity and understanding the primary methods of broken credentials (e.g. phishing) along with applying methods to prevent security incidents.

As it can be noticed, the emerging technologies analyzed present a series of risks regarding sensitive data exposure, the leading causes being incorrect configurations and security measures only partially implemented. Taking into consideration the fact that the practitioners in the accounting field are responsible for the protection of the sensitive data used, it is mandatory for them to develop skills to safeguard the information. Competencies such as efficient use of access rights, ensuring data confidentiality and integrity when transmitted outside the company, developing suitable controls to monitor and prevent possible leakages and respecting the security framework of the organizations are meant to prevent security incidents.

We must be aware that the companies are responsible for protecting against data leakages and this can be done by ensuring that the employees are aware of the risks associated with sensitive data exposure and can protect the information. Moreover, a continuous management of the security systems must be in place as the cyberattacks are growing at the same rate as the newest information technologies.

\section{Research methodology}

Worldwide the accounting profession is subject to change due to the evolution of computer science field. In this regard, this study focuses on analyzing on one side the leading information technologies that have the potential to change the profession by facilitating processes and requiring new skills from the accountants. On the other side, it assesses the perception of practitioners towards these technologies, by analyzing their level of awareness and knowledge regarding cloud computing platforms, Big Data, data analytics, mobile technologies as well as related security challenges. 
This empirical research aims to reveal whether aspiring and professional Romanian accountants have a sufficient level of understanding emerging technologies along with the related benefits and challenges in the accounting field. For this purpose, we have designed a survey addressed to practitioners working in audit and accounting departments, conducted during January and February 2017, receiving 115 valid answers.

The questionnaire included 18 items focusing on their education, professional activity and perception towards emerging technologies and related information security risks.

\subsection{Sample characteristics}

All participants have an experience of at least one year in the accounting or audit field. For obtaining homogenous results, the participants of the study were also chosen on work experience considerations.

Table 1. Age and work experience of the participants

\begin{tabular}{ccc}
\hline No. of participants & Age & Work experience \\
\hline $48(41.73 \%)$ & Between 22 and 28 years & Between 1 and 3 years \\
$24(20.89 \%)$ & Between 26 and 31 years & Between 4 and 6 years \\
$12(10.43 \%)$ & Between 29 and 37 years & Between 7 and 10 years \\
$31(26.95 \%)$ & Between 31 and 58 years & More than 10 years \\
\hline \multicolumn{3}{c}{ Source: own processing }
\end{tabular}

From the total of 115 practitioners, $85 \%$ of the respondents are female, result that highlights the preponderance of women in this profession. Regarding the area of business, 105 respondents, representing $90.5 \%$ of the total sample, are working in financial accounting departments, while 13 persons (11.2\%) are operating in financial audit and the rest of participants (3.3\%) are employed in internal audit departments.

By analyzing their level of education, $64.7 \%$ of the respondents finalized their academic training after the master study programs, $28.4 \%$ graduated only from bachelor study programs and $4.3 \%$ have a $\mathrm{PhD}$., while the rest of $2.6 \%$ has postgraduate studies.

Regarding the affiliation of the interviewees with professional bodies, the results showed that the majority (62 persons) is represented by aspiring professionals. 33 of them are enrolled in ACCA courses and 29 are attending CECCAR (Body of Expert and Licensed Accountants of Romania) and CAFR (Chamber of Financial Auditors of Romania) training programs for becoming certified accountants and auditors. $31 \%$ of the respondents are already members of national professional bodies, while only 
3 participants are ACCA qualified practitioners. The rest of $20.4 \%$ have no affiliation with national or international professional organizations.

\section{Findings and discussions}

As a starting point, the respondents have been asked to assess their level of knowledge regarding cloud computing, Big Data and data analytics as well as mobile technologies, using a 4 points Likert scale $(1$ - no experience at all, 2 - theoretical knowledge, 3 - average working capabilities and 4 - proficiency level).

The results of the study emphasize that the participants consider they have an above average knowledge level regarding mobile devices, result that shows the respondents preferences for these technologies. Cloud computing skills are assessed as being below average, while the participants stated that they have on average only theoretical knowledge about Big Data and data analytics.

Regarding the self-assessed level of working capabilities with cloud computing platforms, the result is favorable as cloud computing are still considered an emerging technology in the accounting field. The fact that some of the respondents perceive themselves as having operational capacities with cloud platforms shows that they have already worked with this technology. This result is in line with the expectation as prior research has demonstrated the need for organizations to adopt cloud solutions, even in accounting departments (Ionescu et al., 2014; Caldarelli et al., 2017).

As Big Data and data analytics are not yet extremely used in the accounting field, the result cannot be seen as either negative or favorable. One main reason for this result might be the fact that the accountants have not received sufficient information during academic studies or trainings on this extremely important topic (ACCA, 2013a; Stanciu \& Rindașu, 2017). However, this emphasizes that professionals should focus more on these technologies because are considered to be a game changer for the accounting profession. The results of the data analysis are presented in the table below (table 2). As it can be observed, in the case of cloud computing platforms, the participants assessed themselves as having on average more than only theoretical knowledge. Nevertheless, $22.61 \%$ of the persons surveyed don't have any exposure to these technologies and only $11 \%$ consider they have proficient working capabilities. 
The results obtained for Big Data and data analytics prove these technologies are less used in comparison with the others, as the majority of practitioners consider that they do not have any exposure to these technologies, while only $5 \%$ of the group self-assessed the abilities as being advanced. The self-perceived working capabilities with mobile technologies are considered to be above average, the majority (60\%) of the respondents estimated it has a proficiency level of knowledge. This result can be easily explained by the preference of people to use mobile technologies such as smartphones or tablets in everyday life. On the other hand, prior research has also emphasized that mobile technologies gain more popularity in accounting and finance departments (Tudoran \& Ionescu, 2014; Kearns, 2017). The same predilection can be observed in the chart below.

Table 2. Self-perceived knowledge level of emerging technologies

\begin{tabular}{lccc}
\hline & $\begin{array}{c}\text { Cloud computing } \\
\text { platforms }\end{array}$ & $\begin{array}{c}\text { Big Data and data } \\
\text { analytics }\end{array}$ & $\begin{array}{c}\text { Mobile } \\
\text { technologies }\end{array}$ \\
\hline AVERAGE & 2.28 & 1.90 & 3.32 \\
STDEV & 0.94 & 0.86 & 0.82 \\
MIN. & 1 & 1 & 1 \\
NO MIN. & 26 & 43 & 3 \\
FREQ. MIN. & $22.61 \%$ & $37.39 \%$ & $2.61 \%$ \\
MAX. & 4 & 4 & 4 \\
NO MAX. & 13 & 6 & 60 \\
FREQ.MAX. & $11 \%$ & $5 \%$ & $52 \%$ \\
MEDIAN & 2 & 2 & 4 \\
SKEW & 0.25 & 0.68 & -0.95 \\
\hline
\end{tabular}

Source: own processing

To assess the working capabilities with accounting information systems and emerging technologies, the participants were asked to choose the technologies that they have used to perform their work-related duties, from the following: ERP systems, cloud computing platforms, Big Data and analytics and mobile technologies.

As it can be observed from the below chart, ERP systems and mobile technologies are used by more than $60 \%$ of the respondents, while only $37 \%$ of the group uses for professional activities cloud computing platforms. Big Data and data analytics are less used by practitioners, as only $20 \%$ of the participants are working with these technologies. In the case of ERP systems the value is in line with the expectations as this technology has been used for more than 20 years by the professional accountants. The overall results are similar to the conclusions made by professional 
bodies and researchers and emphasize that emerging technologies like cloud computing and Big Data are not yet used by practitioners on a large scale. Nonetheless, this outcome also reflects that the adoption of mobile technologies has already started in the accounting field, in the case of Romania, as stated by prior research, in the local context (Stanciu, 2012; Tudoran \& Ionescu, 2014).

Figure 1. Technologies used by respondents

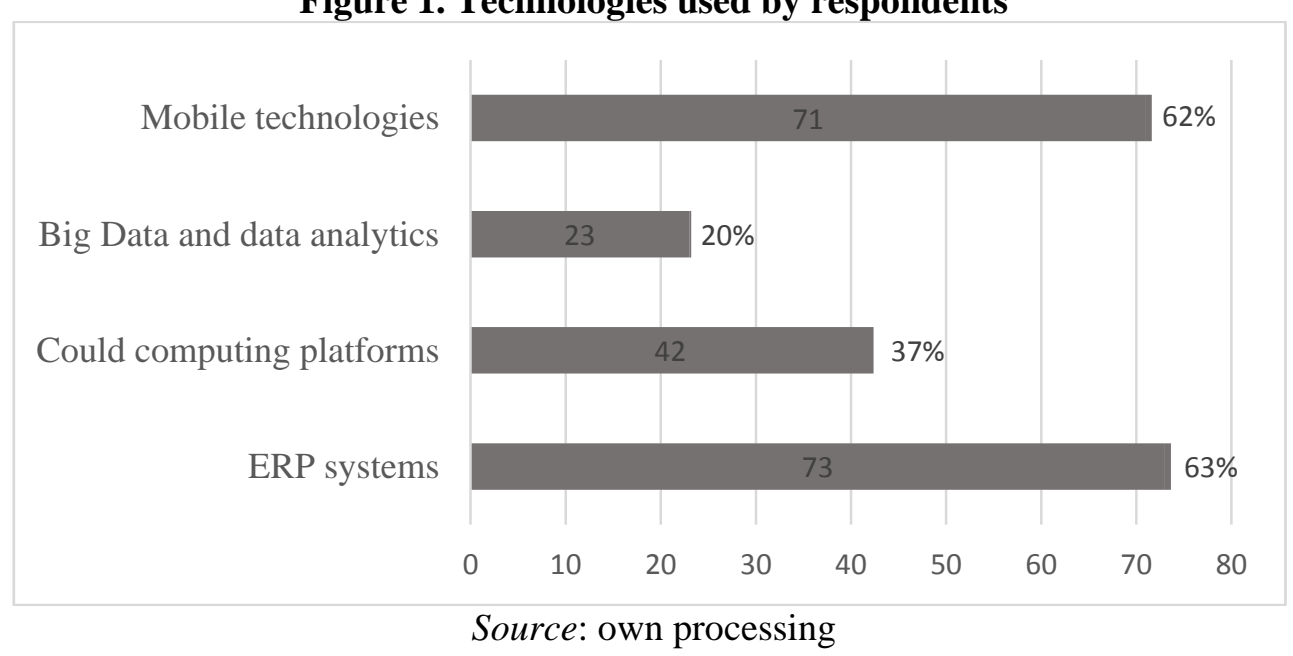

When asked about the impact of emerging technologies on the future of the accounting profession, more than half of the respondents considered that cloud computing platforms and mobile technologies would have a significant impact. This result is in line with the forecasts of previous studies (ACCA, 2013a; ICAEW, 2015). However, in the case of Big Data and analytics they stated that the impact would be above average (chart 2). This outcome can be explained by the fact that previous results have underlined that the participants of these survey do not have enough knowledge on Big Data and data analytics. 
Figure 2. Perceived impact of emerging technologies in the accounting field

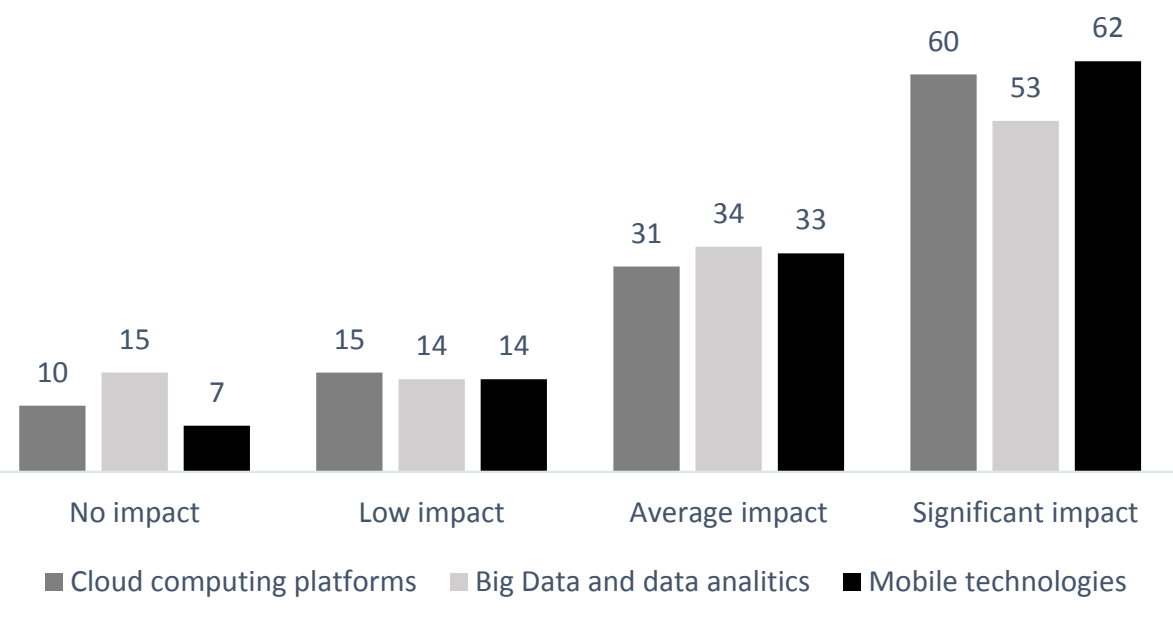

Source: own processing

This outcome is in line with the forecast made by ACCA (2013c) in the studies conducted in the field of emerging technologies and proves that the professionals are aware of the shifting trends in the accounting field. By analyzing together, the results from these two questions in regards of Big Data and data analytics, we can state that overall the practitioners are aware of the impact that these technologies can have (Al-Htaybat \& Alberti-Alhtaybat, 2017), despite the fact that the majority of the respondents do not possess excellent operational skills (Scheponik et al., 2016; Walterbusch et al., 2017).

The next part of the survey has focused on assessing the benefits brought by the emerging technologies. As it was presented in the literature review, these technologies have common advantages, as real-time reporting possibility and 24/7 access to data, but they also have some specific benefits. The participants were asked to assess on 5 points Likert scales ( 1 - not significant, 5 - extremely significant), the importance of the advantages brought by these technologies. The centralized results regarding the benefits associated with the emerging technologies analyzed are presented in the table below (table 3 ). 
Table 3. Assessed importance of emerging technologies benefits

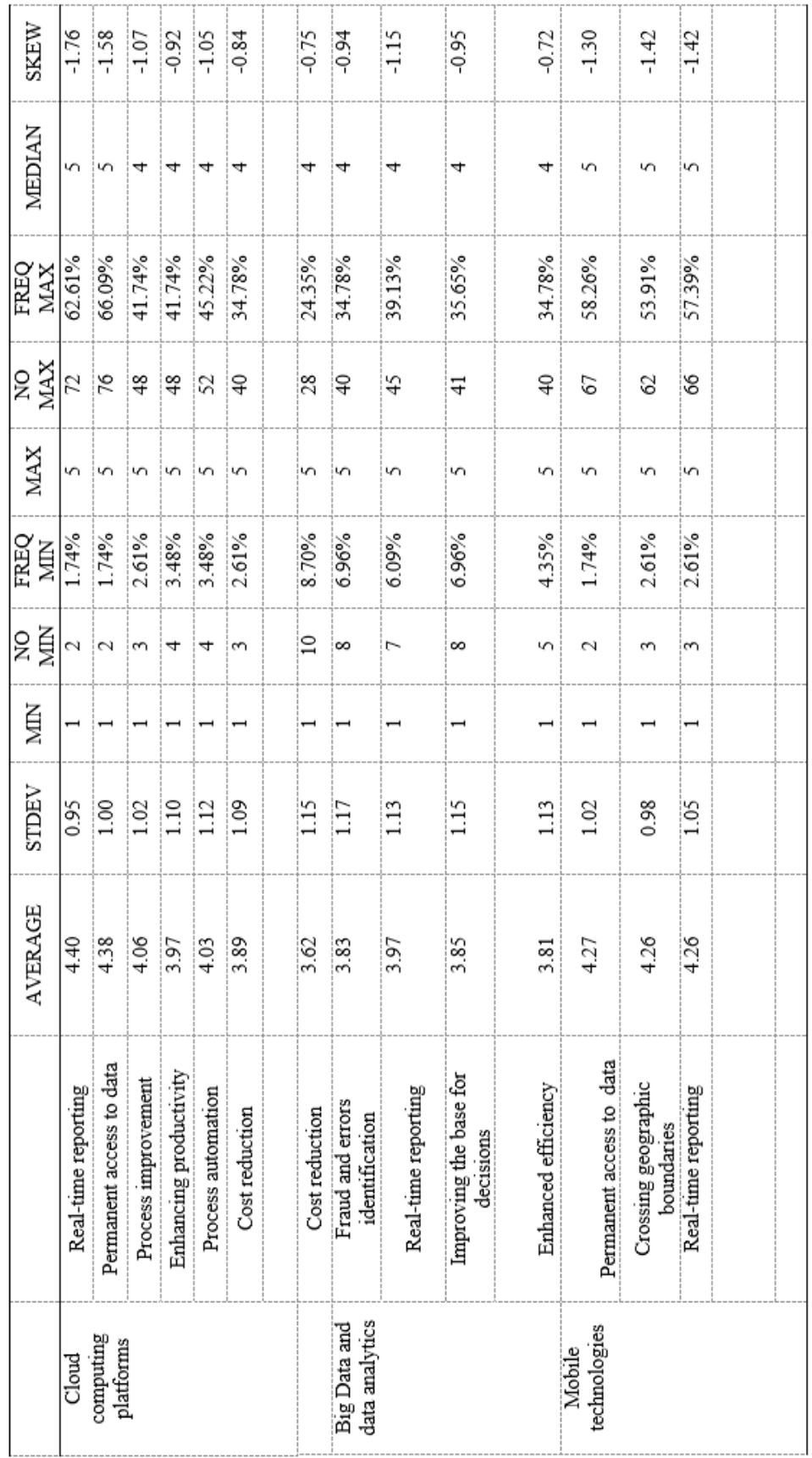

Source: own processing 
Analyzing the assessment of advantages for cloud computing platforms, compared with in-house solutions for accounting purposes, over $60 \%$ of the respondents considered that real-time reporting possibilities and continuous access to data are significant advantages. These results were expected from the participants as previous studies have shown that the real-time reporting process is considered extremely favorable (ACCA, 2013d) because it is deemed to bring greater value to the organizations. The next advantages, as per the opinion of the respondents were: process automation, increased level of productivity and improvement of processes. The last item, economies of scale, was assessed as also having an above average importance.

Overall, regarding these six benefits for cloud platforms, it can be stated that the participants are aware of their advantages and understand the need for real-time reporting, which as it has been said previously, became a crucial need for companies. Moreover, this result is in line with the prior studies, conducted by Capgemini (2012) and ACCA (2013a), regarding the benefits brought by this technology. As per this, we can state that the alignment of the Romanian accounting profession with the expectation of international professional bodies has started. Still, there are more steps to be done, especially if the practitioners want to be proficient with this technology.

In the opinion of the respondents, the main advantage of Big Data and data analytics is represented by real-time reporting possibilities $-39.13 \%$ of the persons surveyed consider as extremely significant, while $35.65 \%$ assess its importance as being above average. The second one is the capability of identifying frauds and errors more accurately in a shorter period, followed by a better support for the decision-making process, the last one being cost reduction. Nonetheless, all four items are considered to have an above average significant. This result was in line with our expectations as the worldwide general trend in the accounting profession was to embrace this technology (CGMA, 2013; ACCA, 2013b), due to its potential of being a game changer.

Regarding the advantages related to mobile technologies, the most important item in the participants' opinion is the permanent access to data, followed then by two items with the same important impact: the real-time reporting options and the fact that these devices bring borderless connectivity. The increased efficiency was the last advantage in the rank as per the respondents. Nonetheless, as in the case of cloud computing platforms and Big Data and data analytics, all benefits have been graded as having an above average importance.

The participants have also been asked to assess the challenges associated with the analyzed technologies, to determine their level of awareness in regards to the potential risks. For each technology particular threats have been given, most of them presented in the previous part of the paper. We have used 5 points Likert scales questions $(1$ - not important, 5 - extremely significant). 
For cloud computing platforms, the respondents had to evaluate the following items: sensitive data exposure, unauthorized access, lack of access and physical security of data. As per the assessment made by the professionals, in their opinion the most significant issue is represented by sensitive data exposure, result that it is in line with the practical reality in the absence of proper security measures, like strong encryption algorithms, weak credentials and unmonitored access (Ionescu et al., 2014; Joshi et al., 2017). This outcome is confirming prior studies (ACCA, 2016) and reveals the awareness of the Romanian accounting profession regarding information security.

The second challenge is represented by the unauthorized access and this is usually caused by incorrect access privileges allocation, weak credentials and the lack of a set of best practices for users. This concern is founded as previous studies have shown that unauthorized access is still one of the most significant vulnerabilities (Johns, 2016). The physical security was the next concern in line for participants regarding the significance and their assessment is correct as usually in the case of cloud platforms, as the client doesn't have full visibility and access to the data warehouse. However, by the best practices of cloud providers, all data must be protected against unauthorized physical access. Nevertheless, in the case of associating clod application with mobile technologies, the matter of physical security has to be also addressed to the employees that are using these mobile technologies (Scheponik et al., 2016). This fact reinforces the idea that accountants play a vital role in maintaining data privacy.

The last threat is the lack of access to data. This challenge, like the others three, has been assessed as having an above average importance. As 24/7 data availability was considered by the respondents as being the second most significant advantage, there is a slight deviation in the trend as security issues have replaced the importance of continuous access. This result was in line with our expectations, as security matters should always come first.

After analyzing the assessments of possible cloud platforms vulnerabilities, it can be considered that the respondents understand and are aware of the potential impact that security risks might have, conclusion that is in line with the studies performed by professional bodies on cyber-security issues. Big Data and data analytics challenges have been rated as well, by the persons surveyed and as in the case of cloud platforms, sensitive data exposure is the first item of concern for professionals, followed by the lack of proper security measures that are vital in the case of significant volumes of data. The third item, as per the assessment, was represented by technological restrictions, such as limited computer power and proper storage. The last risk was considered to be the lack of access, result that is in line with the cloud platforms risks presented above. As per our expectations, the respondents demonstrated a reasonable level of knowledge in regards to the most important challenges of Big Data, as presented in the literature review. 
For mobile technologies, the greatest threat in the perception of the participants is the low-level security of mobile applications and this result proves that the professionals surveyed are aware not only of the benefits of mobile applications, but they also understand the risks associated. This matter usually comes in the case of own devices usage that might not have additional security measures in place. The last two items have been assessed as equals: unauthorized access and physical security, both of which can be avoided by implementing multiple steps authentication (e.g. fingerprints and password), which can prevent data exposure if the mobile device is lost or stolen. Prior research in the local context had highlighted the general trend of BYOD approach (Stanciu, 2012), but also at international level (Morrow, 2012; Thielens, 2013) can lead to a decrease in the security of data.

The overall results show that respondents are concern by the security aspects that these technologies can bring. As per this, we can conclude that there had been improvements in the level of awareness regarding cyber-security, in the accounting profession. This outcome is in line with prior studies conducted by the international accounting bodies (ICAEW, 2013; ACCA, 2016). When asked if they are using a mobile device for performing their job-related tasks, $61.73 \%$ answered positively, an outcome that indubitably proves that mobile technologies have started to be utilized by the accounting and audit professionals for their job activities. From the total of 71 persons, 55 are using their own mobile devices, while the rest use devices provided by their organizations. This result shows that the BYOD concept is also applying in Romania, aspect that can be seen as positive, as long as proper security measures are implemented. However, at this question, 42 respondents declared that they had received a mobile device from the company, but as it can be observed above, only 16 persons are using that device for work-related tasks. In this case, there is the possibility that organizations are offering mobile devices to their employees not only for work-related purposes but as a benefit in kind.

As researchers have shown (Wallace \& Clariana, 2005; Grant et al., 2009; Stanciu $\&$ Tinca, 2016) there are usually gaps between the self-assessed level of working capabilities and the actual reality, in the case of students and fresh graduates. To verify that the self-assessment made by the participants is correctly reflecting their knowledge, we conducted a statistical analysis based on a Point Biserial Correlation in PASW Statistics 18, having as a dichotomous variable the usage or non-usage of a particular technology. As the respondents were asked to self-assess their proficiency level in regards to the presented emerging technologies, those grades were used as $\mathrm{X}$ variables in the analysis performed.

As it can be observed from the statistical analysis presented below, there is a high positive correlation between the self-perceived knowledge level and actual usage in the case of cloud computing platforms, having a correlation coefficient of 0.526 with Sig. 2 -tailed $=0$. This outcome shows that there are no significant gaps between the 
perception and reality of this aspect in matters of cloud computing technologies and indeed the knowledge level of the interviewees is more theoretical than operational.

When applying the same reasoning for Big Data and data analytics, the results obtained show a positive and above average correlation between the perceived and real working skills. Nonetheless, in the case of mobile technologies, the correlation is low, because the participants assessed their level of expertise as being above average, but they are not using these technologies for work-related activities, but rather for personal activities. However, we must keep in mind the fact that overall the participants have proven at least a sufficient level of knowledge in regards to primary benefits and possible challenges as the results in table 3 are highlighting.

Table 4. Correlations between the self-assessed level of proficiency and actual usage

\begin{tabular}{|c|c|c|c|c|}
\hline \multicolumn{2}{|c|}{ Self-perceived knowledge level } & $\begin{array}{c}\text { Cloud } \\
\text { computing } \\
\text { platforms }\end{array}$ & $\begin{array}{c}\text { Big Data and } \\
\text { data } \\
\text { analytics }\end{array}$ & $\begin{array}{c}\text { Mobile } \\
\text { technologies }\end{array}$ \\
\hline \multirow{3}{*}{$\begin{array}{l}\text { Cloud computing } \\
\text { platforms }\end{array}$} & Pearson Correlation & $0.526^{* *}$ & .037 & .119 \\
\hline & Sig. (2-tailed) & .000 & .694 & .205 \\
\hline & $\mathrm{N}$ & 115 & 115 & 115 \\
\hline \multirow{3}{*}{$\begin{array}{l}\text { Big Data and data } \\
\text { analytics }\end{array}$} & Pearson Correlation & .147 & $0.357 * *$ & .016 \\
\hline & Sig. (2-tailed) & .118 & .000 & .862 \\
\hline & $\mathrm{N}$ & 115 & 115 & 115 \\
\hline \multirow{3}{*}{$\begin{array}{l}\text { Mobile } \\
\text { technologies }\end{array}$} & Pearson Correlation & 143 & .042 & $0.244 * *$ \\
\hline & Sig. (2-tailed) & 127 & .652 & .009 \\
\hline & $\mathrm{N}$ & 115 & 115 & 115 \\
\hline **. Correlation is $\mathrm{s}$ & ignificant at the 0.01 level ( 2 & ailed). & & \\
\hline
\end{tabular}

Taking the results into consideration, we conclude that the professional accountants and auditors possess at least a theoretical level of knowledge regarding emerging technologies. However, the theoretical knowledge level has proven to represent a sufficient foundation for recognizing the benefits and the challenges brought by these emerging technologies. The participants also manifested a high degree of awareness in regards to security issues. This outcome demonstrates the general tendency of accounting practitioners of stepping outside of the current borders of the profession by developing new skills in the information technology field, following in this way the recommendations of the professional bodies.

\section{Discussions and conclusions}

Emerging technologies as cloud computing platforms, Big Data, data analytics and mobile technologies, as well as the need for real-time reporting, bring changes to the 
accounting profession. As per this, practitioners have to develop new skills to cope with the changes. Professional bodies and organizations emphasize that the future roles of the professionals will be somewhere between the border of accounting and information technologies expertise, to continue to create value in the digital era. As presented in this paper, the emerging technologies, we focused on, bring significant benefits for both the accountant and organization, by decreasing the volume of simple repetitive activities and focusing more on core operations that create competitive advantages. Nonetheless, along with the benefits, these technologies bring critical challenges that might affect the overall activities of the organization.

The empirical study has shown that aspiring and professional accountants and auditors are becoming familiar with these emerging technologies, but they are not fully mastering them. Despite this, their current level of knowledge has been proven to be sufficient in identifying the primary benefits and challenges. Still, they still need to develop new skills and enhance their expertise to possess efficient working capabilities. As the security of data manipulated by using these technologies is the primary challenge, the participants demonstrated an above average theoretical level of awareness by correctly identifying the main issues.

Regarding the actual adoption of cloud computing platforms, big data and data analytics in the accounting field, the received results point out that their usage is not incredibly spread, in contrary with mobile technologies that have been accepted in a freer manner, probably because of their usage into day to day personal activities. We conclude that even though the aspiring and professional accountants have an average knowledge level on these emerging technologies, a further enhancement of IT related skills must be made, as efficient working capabilities and data protection controls are vital in this new era of digitalization.

The main limitation of this study is represented by the fact that during academic studies, topics like cloud computing, Big Data, data mining and mobile technologies are often missing from the curricula, fact that can explain a given level of foreignness regarding these technologies. Moreover, as per this aspect, professionals are required to use these technologies without proper awareness of the benefits and challenges, circumstance that may have affected the correct identification of the advantages and drawbacks.

For gaining a better level of understanding and working capabilities with these emerging technologies, we consider that academic environment plays a vital role, because it makes the future professionals familiar with emerging technologies during the accounting and finance process of learning. By linking accounting and IT topics, we believe that aspiring accountants will develop a greater level of knowledge. Nevertheless, we must also keep in mind the fact that not only the academic environment and professional bodies should try and familiarize the professionals, but also themselves must seek to adapt their skills as per the organization's requirements, by attending training and being up to date on emerging topics, such as these. 
As a future direction, we believe it will be relevant to investigate how current activities of entry and middle-level accounting practitioners might be replaced by these technologies, with the help of process automation. In this way, we might be able to prevent temporary differences by pointing out how the profession can readjust its skills.

\section{Acknowledgements}

The paper was presented in the $12^{\text {th }}$ International Conference Accounting and Management Information Systems AMIS 2017, Bucharest, Romania and the authors benefited of the debates and recommendations of the participants. The present paper integrates the recommendations and feedbacks of the specialists participating to the conference.

\section{References}

Al-Htaybat, K. \& von Alberti-Alhtaybat, L. (2017) "Big Data and corporate reporting: impacts and paradoxes", Accounting, Auditing \& Accountability Journal, vol. 30, no.4: 850-873

Armbrust, M., Fox, A., Griffith, R., Joseph, A.D., Katz, R.H., Konwinski, A., Lee, G., Patterson, D.A., Rabkin, A., Stoica, I. \& Zaharia M. (2009) "Above the Clouds: A Berkeley View of cloud computing", Technical Report UCB/EECS-2009-28, University of California, Berkeley

Bradley, J., Loucks, J., Macaulay, J., Medcalf, R. \& Buckalew, L. (2012) „BYOD: A Global Perspective, Harnessing Employee-Led Innovation”, available online at http://www.cisco.com/c/dam/en_us/about/ac79/docs/re/BYOD _Horizons-Global.pdf (accessed March $15^{\text {th }}$ 2017)

Brandas, C., Megan, O. \& Didraga, O. (2015) "Global perspectives on accounting information systems: mobile and cloud approach", Procedia Economics and Finance, no. 20: 88-93

Buyya, R., Broberg, J. \& Goscinski, A. M. (2010) Cloud computing: Principles and paradigms, John Wiley \& Sons

Caldarelli, A., Ferri, L. \& Maffei, M. (2017) "Cloud Computing Adoption in Italian SMEs: A Focus on Decision-making and Post-implementation Processes", Reshaping Accounting and Management Control Systems, 53-76

Capgemini (2012) "Business Cloud: The State of Play Shifts Rapidly", http://www.de.capgemini.com/insights/publikationen/business-cloud-thestate-of-play-shifts-rapidly/ (on-line access: August $04^{\text {th }}$ 2017)

Carroll, M., Alta Van Der M. \& Paula K. (2011) "Secure cloud computing: Benefits, risks and controls", Information Security South Africa (ISSA), 1-9 
Chartered Global Management Accountant (2013) "From insight to impact: Unlocking opportunities in big data", http://www.cgma.org/resources /reports/downloadabledocuments/from-insight-to-impact-unlocking-theopportunities-in-big-data.pdf (on- line access: August 04 ${ }^{\text {th }}$ 2017)

Chorafas, D.N. (2008) IT auditing and Sarbanes-Oxley compliance: key strategies for business improvement, New York: CRC Press

Cokins, G. (2013) "Driving acceptance and adopting of business analytics", Journal of Corporate Accounting and Finance, vol. 24, no. 2: 69-74

Deloitte (2013) Understanding the bring-your-own-device landscape, https://www2.deloitte.com/content/dam/Deloitte/uk/Documents/aboutdeloitte/deloitte-ukunderstanding-the-bring-yourowndevice\%20landscape.pdf (on-line access: November $30^{\text {th }} 2016$ )

European Union (1995) Directive 95/46/EC of the European Parliament and of the Council on the Protection of Individuals with Regard to the Processing of Personal Data and on the Free Movement of Such Data, 24 October 1995, http://www.refworld.org/docid/3 ddcc1c74.html (on-line access March $15^{\text {th }}$ 2017)

European Union (2016) Regulation 2016/679 of the European Parliament and of the Council of 27 April 2016 on the protection of natural persons with regard to the processing of personal data and on the free movement of such data, and repealing Directive 95/46/EC (General Data Protection Regulation) Official Journal of the European Union, Vol. L119/59, http://eurlex.europa.eu/eli/reg/2016/679/oj (online access: March 15 ${ }^{\text {th }}$ 2017)

EY (2014) "Ready for takeoff? Overcoming the practical and legal difficulties in identifying and realizing the value of data", http://performance.ey.com/2014/03/31/ready-takeoff/ (on-line access: November $30^{\text {th }} 2016$ )

FBI (2012) "Smartphone Users Should Be Aware of Malware Targeting Mobile Devices and the Safety Measures to Help Avoid Compromise", https://archives.fbi.gov/archives/sandiego /press-releases/2012/smartphone -users-should-be-aware-of-malware-targeting-mobile-devices-and-thesafety-measures-to-help-avoid- compromise (online access: November $24^{\text {th }}$ 2016)

Frey, C. \& Osborne, M. (2013) "The Future of Employment: How susceptible are Jobs to Computerisation." Oxford University Programme on the Impacts of Future Technology Giordanelli, R. \& Mastroianni C. (2010) „The cloud computing paradigm: Characteristics, opportunities and research issues", Istituto di Calcolo e Reti ad Alte Prestazioni (ICAR)

Gizmodo (2014) "Report: Apple Knew of Security Problems Long Before iCloud Breach", http://gizmodo.com/report-apple-knew-of-security-problems-long -before-icl-1638746390 (online access: November $26^{\text {th }} 2016$ )

Gold, S. (2011) "Cracking wireless networks", Network Security, no. 11: 14-18 
Grant, D.M., Malloy, A.D. \& Murphy, M.C. (2009) "A comparison of student perceptions of their computer skills to their actual abilities", Journal of Information Technology Education, vol. 8, no. 1: 141-160

Huang. T.C-K, Wang, T. \& Tsai, Y. T. (2016) "Market reactions to Big Data Implementation Announcements", Pacific Asia Conference on Information Systems, 321-327

IBM (2009) „Public clouds, private clouds and your security”, https://www.ibm.com/ibm/files /Z702257B23536P19/15PPCLOUD COMPUTING_116KB.pdf, (on-line access: October $15^{\text {th }} 2016$ )

ICAEW (2013) "Audit Insights: cybersecurity. Closing the cyber gap", https://www.icaew.com/ /media/corporate/files/technical/audit\%20and\% 20assurance/audit\%20insights/icaew_audit_insights_cyber_security_web. ashx (on-line access: November $30^{\text {th }} 2016$ )

ICAEW (2015) "Providing leadership in a digital world", http://www.icaew.com//media/corporate/files/technical/information-technology/technology/ providing-leadership-digital-full-report.ashx (on-line access: October $10^{\text {th }}$ 2016)

Ionescu B., Ionescu I., Tudoran L. \& Bendovschi A. (2013) "Traditional accounting vs. Cloud accounting", Proceedings of the $8^{\text {th }}$ International Conference Accounting and Management Information Systems, 106-125

Ionescu, B. \& Bendovschi, A. (2014) "Feasibility study on the implementation of cloud computing technology in the information systems of small and medium enterprises", Audit Financiar, no. 3: 40-51

Ionescu, B., Prichici, C. \& Tudoran, L. (2014) "Cloud Accounting-A Technology that may Change the Accounting Profession in Romania", Audit Financiar, no. 2: 3-15

Johns, J. (2016) "Changing the Perspective of Information Security in the Cloud: Cloud Access Security Brokers and Cloud Identity and Access Management", SANS Institute, https://www.sans.org/reading$\mathrm{room} /$ whitepapers/cloud/changing-perspective-information-security-cloudcloud-access-security-brokers-cl-37150 (on-line access: August 04th 2017)

Johns, T. \& Gratton, L. (2013) “The third wave of virtual work", Harvard Business Review, no. 1: 66-73

Jones, S., Irani, Z., Sivarajah, U. \& Love, P. E. (2017) "Risks and rewards of cloud computing in the UK public sector: A reflection on three rganisational case studies", Information Systems Frontiers, 1-24

Joshi, B., Joshi, B. and Rani, K. (2017) "Mitigating Data Segregation and Privacy Issues in Cloud Computing", Proceedings of International Conference on Communication and Networks. Springer, Singapore, 175-182

Kearns, G. (2016) "Countering Mobile Device Threats: A Mobile Device Security Model", Journal of Forensic \& Investigative Accounting, vol. 8, no. 1: $36-48$

Laney, D. (2001) "3D data management: Controlling data volume, velocity and variety”, META Group Research Note, 6: 70 
Mangiuc, D. (2017) "Accountants and the cloud-Involving the professionals", Accounting and Management Information Systems, vol. 16, no. 1: $179-198$

Mayer-Schönberger, V. \& Cukier, K. (2013) "Big data: A revolution that will transform how we live, work, and think", Houghton Mifflin Harcourt

McKnight, C. (2015) "Preliminary investigation of big data and implications for accounting curricula", Auckland Regional Accounting Conference

Mell, P. \& Grance, T. (2009) "The NIST definition of cloud computing", National Institute of Standards and Technology, no 6: 50

Morrow, B. (2012) "BYOD security challenges: Control and protect your most sensitive data", Network Security, 5-8

PCAOB (2010) "Auditing Standard No. 12 - Identifying and Assessing Risks of Material Misstatement", http://pcaobus.org/Standards/Auditing/Pages/ Auditing_Standard_12.aspx (on-line access: February $\left.15^{\text {th }} 2017\right)$

PWC (2016) "Toward new possibilities in threat management", http://www.pwc.com/ee/et/publications/pub/gsiss-report-cybersecurityprivacy-possibilities.pdf (on-line access: March 2 2017)

Richins, G., Stapleton, A., Stratopoulos, T. C. \& Wong, C. (2016) „Data Analytics and Big Data: Opportunity or Threat for the Accounting Profession?", https://papers.ssrn.com/sol3/papers.cfm?abstract_id=2813817 (on-line access: November $28^{\text {th }} 2016$ )

Russom, P. (2011) „Big data analytics”, TDWI Best Practices Report, Fourth Quarter, 1-35

Sas.com. (2013) „Big Data: What it is and why it matters”, https://www.sas.com/en_us/insights/big-data/what-is-big-data.html (on-line access: November $26^{\text {th }} 2016$ )

Scheponik, T., Sherman, A. T., DeLatte, D., Phatak, D., Oliva, L., Thompson, J., \& Herman, G. L. (2016), "How students reason about Cybersecurity concepts", Frontiers in Education Conference, 1-5

Shayan, J., Azarnik, A., Chuprat, S., Karamizadeh, S. \& Alizadeh, M. (2013), „Identifying Benefits and risks associated with utilizing cloud computing”, The International Journal of Soft Computing and Software Engineering [JSCSE], vol. 3, no. 3: 416-421

Singh, C., Shelor, R., Jiang, J. \& Klein, G. (2004) "Rental software valuation in IT investment decisions", Decision Support Systems, vol. 38(1): 115-130

Stanciu, V. (2015) "Considerations Regarding Financial Audit in the Big Data Era", Audit Financiar, vol. 13, no. 128: 65-71

Stanciu, V. \& Bran, F. P. (2015) "The accounting profession in the digital era", Proceedings of the International Conference Ecological Performance in a Competitive Economy, Supplement of Quality-Access to Success, vol. 16, S1: 546-550 
Stanciu, V. (2012) "IT emerging risks - are the companies prepared to face them?", Proceedings of the 6th International Conference on Globalization and Higher Education in Economics and Business Administration, 601 - 607

Stanciu V. \& Rîndașu S. (2017) "Emerging information technologies in accounting - are the aspiring professional accountants prepared to face the challenges? A case study of Romanian universities", Proceedings of the 29th International Business Information Management Association Conference, $2455-2467$

Stanciu, V. \& Tinca, A. (2016) "Students' awareness on information security between own perception and reality-an empirical study", Accounting and Management Information Systems, 15(1): 112-130

Stieglitz, S. \& Brockmann, T. (2012) "Increasing organizational performance by transforming into a mobile enterprise", MIS Quarterly Executive, 11(4): 189-205.

The Association of Chartered Certified Accountants (2013a) "Digital Darwinism: thriving in the face of technology change", http://www.accaglobal.com/ content/dam/acca/global/PDF-technical/futures/pol-afa-tt2.pdf (on-line access: October 10 $0^{\text {th }}$ 2016)

The Association of Chartered Certified Accountants (2013b) „Big data: its power and perils", http://www.accaglobal.com/bigdata (on-line access: November $24^{\text {th }}$ 2016)

The Association of Chartered Certified Accountants (2013c) „Technology trends: their impact on the global accountancy profession", http://www.accaglobal. com/content/dam/acca/global/PDF-technical/futures/pol-af-ttti.pdf (on-line access: November $24^{\text {th }}$ 2016)

The Association of Chartered Certified Accountants (2013d) "Understanding investors: the road to real-time reporting", http://www.accaglobal.com /content/dam/acca/global/PDF-technical/ financial-reporting/pol-afbui03.pdf (on-line access: November $24^{\text {th }} 2016$ )

The Association of Chartered Certified Accountants (2016) "Cybersecurity Fighting Crime's Enfant Terrible", http://www.futuretoday.com/ content/dam/IMA/pdf/T (on-line access: February 12 ${ }^{\text {th }}$ 2016)

The Association of Chartered Certified Accountants and Institute of Management Accountants (2015) "The Data Revolution", http://www.futuretoday.com/ technology/data/the-data-revolution.html (on-line access: November $25^{\text {th }}$ 2016)

Thielens, J. (2013) "Why API are central to a BYOD security strategy", Network Security, 5-6

Trigo A., Belfo F. \& Estébanez R.P. (2014) "Accounting Information Systems: The Challenge of the Real-time Reporting", Procedia Technol, no.16: 118-127

Țugui, A. \& Gheorghe, A. M. (2014) "Changing The Role of Accountancy in the Context of Cloud-Computing", Managementul Intercultural, vol.16, no. 2: 149-157. 
Vasarhelyi, M.A. \& Alles, M.G. (2008) "The "now" economy and the traditional accounting reporting model: Opportunities and challenges for AIS research", International Journal of Accounting Information Systems, vol. 9, no. 4: 227-239

Wallace, P. \& Clariana, R. (2005) "Perception versus reality - Determining business students' computer literacy skills and need for instruction in information concepts and technology", Journal of Information Technology Education, 4: 141-151

Walterbusch, M., Fietz, A. \& Teuteberg, F. (2017) "Missing cloud security awareness: investigating risk exposure in shadow IT", Journal of Enterprise Information Management, vol. 30 no 4: 644-665

Watty, K., McKay, J. \& Ngo, L. (2016) "Innovators or inhibitors? Accounting faculty resistance to new educational technologies in higher education", Journal of Accounting Education, no.36: 1-15

Zarei, E., Kheiri, M. \& Yazdgerdi, N. (2014) "The level at which accounting professors use information technology at universities", Journal of Accounting Research, vol. 4 no. 2: 159-174 